\title{
Optical spectroscopy of bismuth-doped pure silica fiber preform
}

\author{
I. Razdobreev, ${ }^{1,2, *}$ H. El Hamzaoui, ${ }^{1,2}$ V. Yu. Ivanov, ${ }^{3}$ E. F. Kustov, ${ }^{4}$ B. Capoen, ${ }^{1,2}$ and M. Bouazaoui ${ }^{1,2}$ \\ ${ }^{1}$ CERLA, FR CNRS 2416, University Lille 1, 59655 Villeneuve d'Ascq, France \\ ${ }^{2}$ PHLAM-IRCICA, UMR CNRS 8523, University Lille 1, 59655 Villeneuve d'Ascq, France \\ ${ }^{3}$ Institute of Physics of Poland Academy of Sciences, 32/46 al. Lotników, 02668 Warsaw, Poland \\ ${ }^{4}$ Moscow Power Engineering Institute (Technical University), 14 Krasnokazarmennaya Street, 111250 Moscow, Russia \\ *Corresponding author: Igor.Razdobreev@univ-lille1.fr
}

Received January 12, 2010; accepted March 10, 2010; posted March 23, 2010 (Doc. ID 122665); published April 22, 2010

We report on the optical spectroscopy of monolithic fiber preform prepared from nanoporous bismuth-doped silica glass. The experiments reveal the existence of at least two different types of active centers and clearly demonstrate that the presence in the glass matrix of other dopant is not necessary to obtain the near-IR photoluminescence connected to Bismuth. (C) 2010 Optical Society of America

OCIS codes: $140.3510,140.3380,300.6250$.

Bismuth-doped silica glasses since the discovery of their near-IR (NIR) photoluminescence (PL) [1] attract much attention owing to the potential fiber laser applications [2-4]. Although the luminescent center (or centers) is not clearly identified up to now there exist some hypotheses and even numerical models that involve directly such a codopant as $\mathrm{Al}$ in the environment of $\mathrm{Bi}$ ions [5-7]. As a consequence we should recognize that not only the valence state of bismuth in a glass matrix should be the subject of investigation but also the role of other dopant. Recently we have demonstrated that the codoping of $\mathrm{SiO}_{2}: \mathrm{GeO}_{2}: \mathrm{P}_{2} \mathrm{O}_{5}$ preforms with $\mathrm{Al}$ was not necessary to "activate" the PL at $1300 \mathrm{~nm}$, though the latter was temperature sensitive and disappeared after high-temperature annealing $[8,9]$.

In the present Letter we report the results on $\mathrm{cw}$ $\mathrm{PL}$ and PL kinetics in a sintered $\mathrm{SiO}_{2}: \mathrm{Bi}(\mathrm{SB})$ preform that does not contain any other dopant. The observed features make it possible to conclude that the NIR PL in Bi-doped silica glasses is caused by the specific environment of bismuth ions, and it does not connect, at least directly, to $\mathrm{Al}, \mathrm{Ta}, \mathrm{Ge}, \mathrm{P}$, or any other codoping.

The nanoporous (NP) silica glass was prepared using a sol-gel technique from tetraethyl orthosilicate under base-catalysis conditions [10]. Such a silica material exhibits interconnected pores of mean diameter $24 \mathrm{~nm}$, a specific surface area of $130 \mathrm{~m}^{2} / \mathrm{g}$, and a pore volume of $0.57 \mathrm{~cm}^{3} / \mathrm{g}$. The above parameters were determined by isothermal nitrogen sorption measurements [11]. Two samples from NP silica glass were prepared: the control sample without bismuth doping (CS) and Bi-doped (SB) using conventional solution doping technique. After the dehydroxylation procedure under chlorine/oxygen atmosphere the samples were sintered at $1300^{\circ} \mathrm{C}$ under helium atmosphere resulting in a transparent and colorless monolithic cylindrical preforms of $5 \mathrm{~mm}$ diameter. The molar ratio $\mathrm{Bi} / \mathrm{Si}$ inside the preform was determined by the wavelength (WL) dispersive x-ray spectroscopy analysis, and it was estimated to be around $150 \mathrm{ppm}$. To prepare the CS only the step of solution doping was omitted. Once more, we would like to emphasize that in contrary to $[12,13]$ our preforms are monolithic and can be easily fibered. Also the technology offers the possibility to dope independently the glass matrix before the use of conventional solution doping technique.

The experiments on $\mathrm{cw}$ PL and PL kinetics under pulsed excitation were performed in the photoncounting regime at low temperatures with the use of a single-grating monochromator M266 (Solar LS) equipped with a cooled photomultiplier R5509-73 (Hamamatsu, Inc.). The photomultiplier was coupled to the multistop scaler P7887 (Fast ComTec). All cw PL spectra were corrected for the spectral response of the system.

In Fig. 1 we present the absorption spectra of CS and SB. Only two absorption bands at $380 \mathrm{~nm}$ (A) and at $435 \mathrm{~nm}$ (B) connected to bismuth doping could be clearly identified. The relatively low bismuth concentration and short length of the samples $(\sim 3 \mathrm{~mm})$ do not permit us to reveal other absorption bands in the visible and NIR regions.

In Fig. 2 we presented the normalized PL spectra under excitation at $325 \mathrm{~nm}$ (He-Cd laser, $5 \mathrm{~mW}$ ), at $375 \mathrm{~nm}\left(\mathrm{Ar}^{+}\right.$laser, $20 \mathrm{~mW}$ ), at $405 \mathrm{~nm}$ (laser diode,

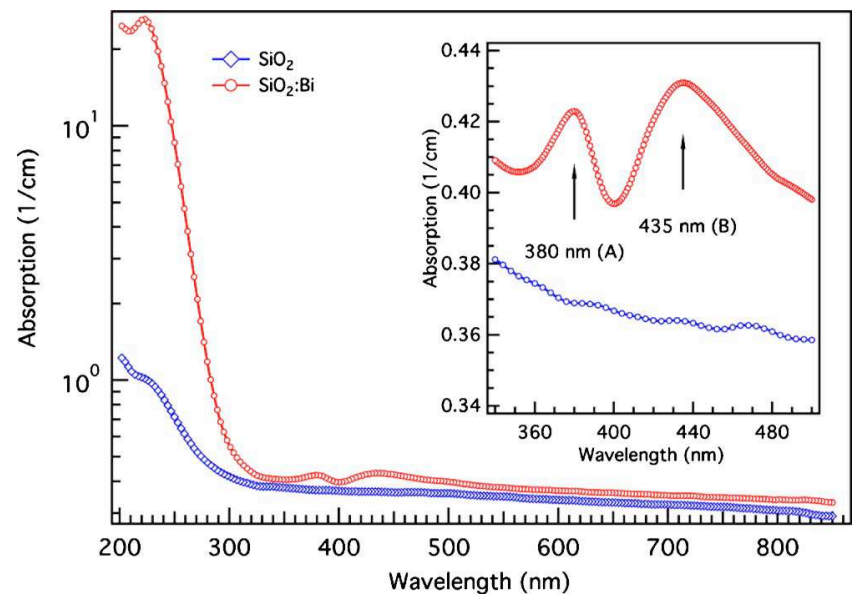

Fig. 1. (Color online) Absorption spectra of CS and SB samples. $T=300 \mathrm{~K}$. 


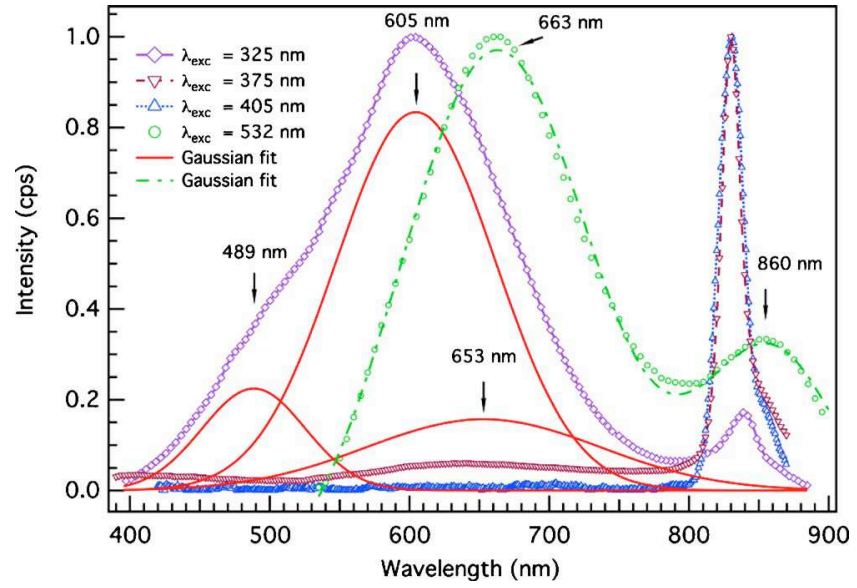

Fig. 2. (Color online) PL spectra of SB preform in the WL region $400-900 \mathrm{~nm}$. $T=10 \mathrm{~K}$.

$30 \mathrm{~mW}$ ), and at $532 \mathrm{~nm}$ (Cobolt, $20 \mathrm{~mW}$ ) in the region of $400-900 \mathrm{~nm}$. Under excitation at $325 \mathrm{~nm}$ two bands could be recorded: the large band peaked at $603 \mathrm{~nm}$ with an FWHM of about $160 \mathrm{~nm}$ and a weak band peaked at $838 \mathrm{~nm}(\mathrm{FWHM}=34 \mathrm{~nm})$. The former band has a complex structure and can be decomposed in three Gaussian bands, as shown in the figure. The increase of the excitation WL leads to the disappearance of this band so that under direct excitation in the absorption band A the strong band peaked at $830 \mathrm{~nm}$ with an FWHM of about $24 \mathrm{~nm}$ becomes dominant and under excitation at $405 \mathrm{~nm}$ the PL in the range of $450-780 \mathrm{~nm}$ completely disappears. The excitation at $532 \mathrm{~nm}$ reveals two more PL bands: at $663 \mathrm{~nm}$ and $860 \mathrm{~nm}$ with an FWHM of about $150 \mathrm{~nm}$ and $123 \mathrm{~nm}$, respectively (Gaussian fit).

The PL spectra of SB in the NIR spectral region are presented in Fig. 3. When pumped at $808 \mathrm{~nm}$ (laser diode, $100 \mathrm{~mW}$ ) again three bands were registered: at $845 \mathrm{~nm}$ (FWHM $\sim 36 \mathrm{~nm}$ ), at $906 \mathrm{~nm}$ (FWHM $\sim 52 \mathrm{~nm}$ ), and at $1393 \mathrm{~nm}$ with an FWHM $\sim 90 \mathrm{~nm}$ (Gaussian fit). The cw PL spectrum in the NIR region at the excitation WL of $405 \mathrm{~nm}$ was very similar to that obtained at $808 \mathrm{~nm}$ excitation WL, so we did not report it in the figure. Under excitation at $532 \mathrm{~nm}$ three bands could be recorded: at $939 \mathrm{~nm}$

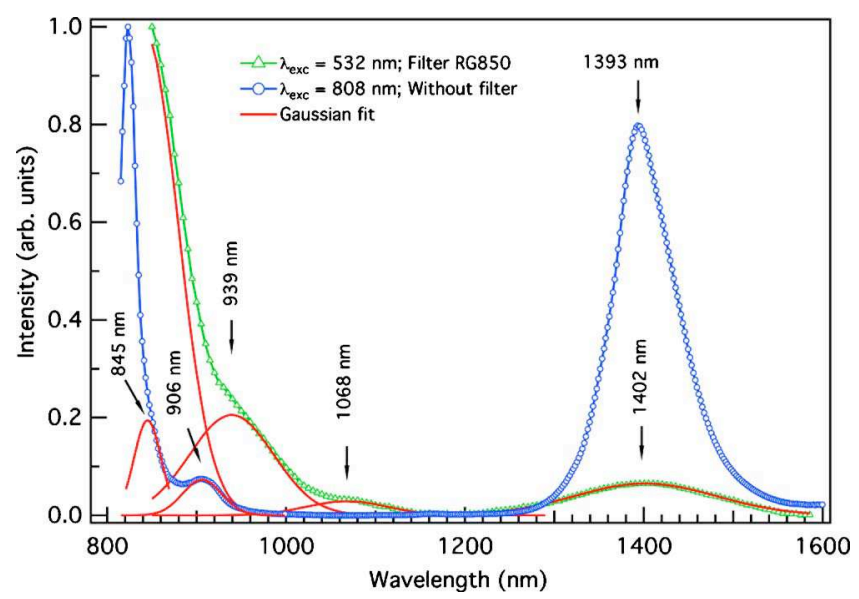

Fig. 3. (Color online) PL spectra of SB preform in the WL region $800-1600 \mathrm{~nm} . T=10 \mathrm{~K}$.
(FWHM $\sim 110 \mathrm{~nm}$ ), at $1068 \mathrm{~nm}($ FWHM $\sim 107 \mathrm{~nm})$, and at $1402 \mathrm{~nm}($ FWHM $\sim 187 \mathrm{~nm})$. The results on cw PL described above allowed us to assume the presence of two luminescence species in SB samples. To check this assumption we performed the detailed measurements of PL kinetics at some specific WLs.

In Fig. 4 we presented the results of PL decay measurements in SB excited with a second-harmonic (SH) of a passively $Q$-switched microchip Nd:YAG laser $(400 \mathrm{ps}, 5 \mathrm{kHz}, 20 \mathrm{~mW}$, time resolution $4 \mathrm{~ns})$. All decay curves are characterized by a short time constants (see the data in the figure) and are well fit to a biexponential decay. In view of the fact of a very good coincidence between a long time constants $\left(\tau_{2} \simeq 6 \mu \mathrm{s}\right)$ for the PL bands at $860 \mathrm{~nm}$ and at $939 \mathrm{~nm}$ we attributed the origin of biexponential decay to the simple superposition of these bands. As it is clearly seen in the figure the $939 \mathrm{~nm}$ band is characterized by the fast decay $\left(\tau_{1} \simeq 0.42 \mu \mathrm{s}\right)$. As for the nonexponential decay at $675 \mathrm{~nm}$ we believe that it is probably the result of a multiple relaxation channels that are possible for this PL band.

For the comparison in Fig. 5 we reported the results on the PL decay measurements under excitation at $810 \mathrm{~nm}(\mathrm{OPO}, 5 \mathrm{~ns})$ and at $532 \mathrm{~nm}(\mathrm{SH}$ of $Q$-switched Nd:YAG, $5 \mathrm{~ns})$. The following features should be noted: (i) although the PL decay at $830 \mathrm{~nm}$ and $910 \mathrm{~nm}$ appears again as a biexponential, its time constants are more than 1 order of magnitude larger (see the data in the figure); (ii) the PL kinetic at $1410 \mathrm{~nm}$ when excited at $810 \mathrm{~nm}$ exhibits a wellresolved rise time of about $140 \mu \mathrm{s}$ that coincides with the long time constant of the PL band at the $830 \mathrm{~nm}$, and the decay perfectly fits a single exponential decline; (iii) the kinetics at $1410 \mathrm{~nm}$ when excited at $532 \mathrm{~nm}$ is nonexponential, and it does not fit even a two exponential decline, which we reported in the figure only for the sake of comparison. Owing to the strong superposition of three bands $(830 \mathrm{~nm}, 845 \mathrm{~nm}$, and $906 \mathrm{~nm}$ ) it is not so obvious to assign the particular time constant to each band, and some more detailed investigation should be performed.

The observed features both in the PL spectra and in the PL kinetics undoubtedly manifest the presence

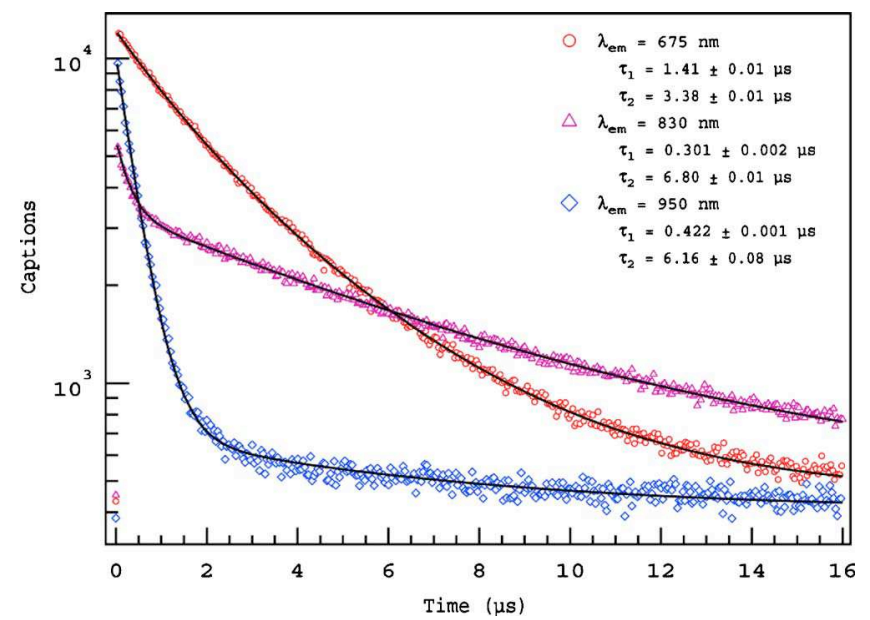

Fig. 4. (Color online) PL kinetics of SB preform at $\lambda_{\text {exc }}$ $=532 \mathrm{~nm} . T=10 \mathrm{~K}$. 


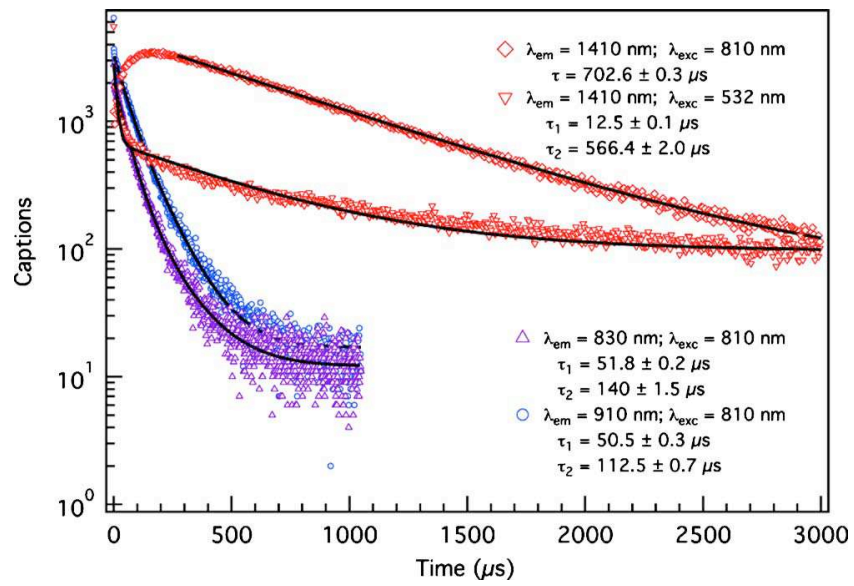

Fig. 5. (Color online) PL kinetics of SB preform at $\lambda_{\mathrm{exc}}$ $=810 \mathrm{~nm} . T=10 \mathrm{~K}$.

of two PL centers connected to bismuth doping. For instance, we attribute to the first one the following PL bands: $830 \mathrm{~nm}, 845 \mathrm{~nm}, 906 \mathrm{~nm}$, and $1393 \mathrm{~nm}$. The observed absorption bands $\mathrm{A}$ and $\mathrm{B}$ also belong to this center. To explain the presence of two distinct luminescent centers connected to bismuth doping a number of hypotheses can be proposed. At first, the presence of $\mathrm{Bi}$ ions in the same valence state is possible but in different environments capable of accommodating it; then the $\mathrm{Bi}$ ions in different valence states and the formation of bismuth pairs cannot be neglected at this level of our knowledge.

The origin of NIR luminescence is not clear yet, and the conclusions are often contradictory. For instance, the hypothesis on the negatively charged interstitial bismuth pairs is based on the presence of $\mathrm{Al}$ in the glass matrix [6], and it is in contradiction to our present experiment. A proposed earlier hypothesis of $\mathrm{Bi}^{+}$-ions [14] is in contradiction to our recent work on the optically detected magnetic resonance (ODMR) [15], because the observed signal is incompatible with the structure of $\mathrm{Bi}^{+}$energy levels (and also with that of $\mathrm{Bi}_{2}^{2-}$ dimer). In the very recent work [16] the authors assigned the NIR emission to the elementary $\mathrm{Bi}^{0}$, but again such an assignment is in contradiction to our experiments on the hydrogen loaded and annealed Bi-doped fibers, which did not present any absorption or luminescence [9]. The presence of two centers in a pure silica glass revealed in the present work implies that the problem of $\mathrm{Bi}$ doped materials is somewhat more complex, and further efforts are necessary to identify the nature of luminescent centers connected to bismuth doping. We
May 1, 2010 / Vol. 35, No. 9 / OPTICS LETTERS

believe that more advanced techniques, such as ODMR, should be exploited to solve the problem.

The authors are grateful to L. Manet for his technical assistance. The work was supported in part by the Conseil Régional Nord/Pas de Calais and the Fonds Européen de Développement Economique des Régions.

\section{References}

1. Y. Fujimoto and M. Nakatsuka, Jpn. J. Appl. Phys. 40, L279 (2001).

2. E. M. Dianov, V. V. Dvoyrin, V. M. Mashinsky, A. A. Umnikov, M. V. Yashkov, and A. N. Gur'yanov, Sov. J. Quantum Electron. 35, 1083 (2005).

3. E. Dianov, A. Shubin, M. Melkumov, O. Medvedkov, and I. Bufetov, J. Opt. Soc. Am. B 24, 1749 (2007).

4. I. Razdobreev, L. Bigot, V. Pureur, A. Favre, G. Bowmans, and M. Douay, Appl. Phys. Lett. 90, 031103 (2007).

5. V. V. Dvoyrin, V. M. Mashinsky, E. M. Dianov, A. A. Umnikov, M. V. Yashkov, and A. N. Guryanov, Absorption, in Proceedings of the 31st ECOC (2005), paper Th 3.3.5.

6. V. O. Sokolov, V. G. Plotnichenko, and E. M. Dianov, Opt. Lett. 33, 1488 (2008).

7. S. V. Firstov, I. A. Bufetov, V. F. Khopin, A. V. Shubin, A. M. Smirnov, L. D. Iskhakova, N. N. Vechkanov, A. N. Guryanov, and E. M. Dianov, Laser Phys. Lett. 6, 665 (2009).

8. I. Razdobreev, L. Bigot, V. Pureur, G. Bowmans, and M. Douay, in Proceedings of the 15th Annual International Laser Physics Workshop (LPHYS'06) (2006), paper 4.5.1.

9. V. G. Truong, L. Bigot, A. Lerouge, M. Douay, and I. Razdobreeev, Appl. Phys. Lett. 92, 041908 (2008).

10. M. Bouazaoui, B. Capoen, H. El Hamzaoui, L. Bigot, and G. Bouwmans, "Monoliths of high-purity silica and its synthesis process," European patent pending EP08370021.1 (2008).

11. E. Berrier, C. Zoller, F. Beclin, S. Turrell, M. Bouazaoui, and B. Capoen, J. Phys. Chem. B 109, 22799 (2005).

12. S. Zhou, N. Jiang, B. Zhu, H. Yang, S. Ye, G. Lakshminarayana, J. Hao, and J. Qiu, Adv. Funct. Mater. 18, 1407 (2008).

13. H.-T. Sun, Y. Miwa, F. Shimaoka, M. Fujii, A. Hosokawa, M. Mizuhata, S. Hayashi, and S. Deki, Opt. Lett. 34, 1219 (2009).

14. X. Meng, J. Qiu, M. Peng, D. Chen, Q. Zhao, X. Jiang, and C. Zhu, Opt. Express 13, 1628 (2005).

15. I. Razdobreev, V. Yu. Ivanov, L. Bigot, M. Godlewski, and E. F. Kustov, Opt. Lett. 34, 2691 (2009).

16. M. Peng, C. Zollfrank, and L. Wondraczek, J. Phys. Condens. Matter 21, 285106 (2009). 